\title{
AVALIAÇÃO VESTIBULOCOCLEAR NA FIBROMIALGIA
}

\section{Vestibulocochlear evaluation in fibromyalgia}

\author{
Bianca Simone Zeigelboim (1), Karlin Fabianne Klagenberg ${ }^{(2)}$, \\ Paulo Breno Noronha Liberalesso ${ }^{(3)}$, Ari Leon Jurkiewicz ${ }^{(4)}$
}

\begin{abstract}
RESUMO
Tema: a fibromialgia é uma síndrome musculoesquelética não inflamatória, de caráter crônico, de etiologia desconhecida, caracterizada por dor generalizada, aumento da sensibilidade na palpação e por sintomas como insônia, rigidez, cansaço, doença psicológica, intolerância ao frio e queixas otológicas. Procedimentos: avaliaram-se no setor de Otoneurologia de uma Instituição, em setembro de 2008, dois pacientes com diagnóstico de fibromialgia, idades entre 52 e 61 anos, sexo feminino, que referiram: tontura, zumbido, sensação de movimento de objetos, desequilíbrio à marcha, quedas, fadiga, depressão, cefaléia, dificuldade em escutar e em movimentar o pescoço, entre outros. Foram submetidos aos seguintes procedimentos: anamnese, inspeção otológica, avaliação audiológica e vestibular por meio da vectoeletronistagmografia. Resultados: observaram-se os seguintes achados: Paciente 1 - perda auditiva do tipo neurossensorial a partir de $2 \mathrm{KHz}$ na orelha esquerda, limiares auditivos dentro dos padrões de normalidade na orelha direita e hipo-reflexia em valor absoluto à prova calórica $42^{\circ} \mathrm{C}$ na orelha direita. Paciente 2 - limiares auditivos dentro dos padrões de normalidade bilateralmente e hiper-reflexia em valor absoluto à prova calórica $42^{\circ} \mathrm{C}$ na orelha direita com intensa manifestação neurovegetativa. Conclusão: os casos apresentados demonstraram a importância das avaliações audiológica e vestibular na contribuição da elaboração de estratégias utilizadas no acompanhamento terapêutico da fibromialgia sugerindo a realização desses exames como rotina clínica.
\end{abstract}

DESCRITORES: Fibromialgia; Vertigem; Testes de Função Vestibular; Audição

\section{INTRODUÇÃO}

A fibromialgia (FM) é uma síndrome musculoesquelética, não inflamatória, de caráter crônico,

(1) Fonoaudióloga; Professora Adjunta do Curso de Fonoaudiologia da Universidade Tuiuti do Paraná, UTP, Curitiba, PR, Brasil; Coordenadora do Programa de Mestrado e Doutorado em Distúrbios da Comunicação da Universidade Tuiuti do Paraná, UTP, Curitiba, PR, Brasil; Doutora e Pós-Doutora em Distúrbios da Comunicação Humana pela Universidade Federal de São Paulo.

(2) Fonoaudióloga; Mestre em Distúrbios da Comunicação pela Universidade Tuiuti do Paraná; Doutoranda em Distúrbios da Comunicação da Universidade Tuiuti do Paraná.

(3) Médico Neurologista do Departamento de Neurologia Infantil do Hospital Pequeno Príncipe e do Laboratório de EEG Digital do Hospital da Cruz Vermelha Brasileira, HCV, Curitiba, PR, Brasil; Mestre em Neurociências pela Universidade Federal de São Paulo; Doutorando em Distúrbios da Comunicação da Universidade Tuiuti do Paraná.

(4) Médico Clínico; Professor do Programa de Mestrado e Doutorado em Distúrbios da Comunicação da Universidade Tuiuti do Paraná, UTP, Curitiba, PR, Brasil; Doutor em Anatomia pela Universidade Federal de São Paulo.

Conflito de interesses: inexistente de etiologia desconhecida, caracterizada por dor generalizada, aumento da sensibilidade na palpação, intolerância ao frio, rigidez, cefaleia, tontura, zumbido, etc ${ }^{1,2}$.

Pesquisas recentes mostram anormalidades bioquímicas, metabólicas e imunorreguladora ${ }^{3}$. $\mathrm{O}$ mecanismo mais aceito para o entendimento fisiopatológico da FM é o de uma alteração em algum mecanismo central de controle da dor o qual poderia resultar em uma disfunção neuro-hormonal. Tal disfunção incluiria uma deficiência de neurotransmissores inibitórios em níveis espinais ou supraespinais (serotonina, encefalina, norepinefrina, etc), ou uma hiperatividade de neurotransmissores excitatórios (substância P, glutamato, bradicinina e outros peptídeos), ou ambas as condições poderiam estar presentes. Essas disfunções poderiam ser desencadeadas por uma infecção viral, estresse mental ou por um trauma físico ${ }^{1}$. Diversas anormalidades têm sido observadas nos portadores de FM ${ }^{4}$, dentre elas, ressaltam-se: a) liberação da substância $P$ (neuro-hormônio) em níveis elevados no líquido cerebrospinal; b) deficiência de serotonina nas 
plaquetas; c) nível baixo de trifosfato de adenosina; d) metabolismo anormal de carboidratos nas hemáceas; e) regulação anormal da produção de cortisol e, f) diminuição de fluxo sanguíneo em determinadas estruturas cerebrais.

Estudos do fluxo sanguíneo cerebral por meio da tomografia computadorizada por emissão de fóton único referem uma diminuição significativa do fluxo sanguíneo nas regiões bilaterais do tálamo e do núcleo caudado ${ }^{1}$.

Pesquisas apontam a influência de fatores genéticos, ambientais e hormonais no desenvolvimento dessa doença e que causam alterações nos níveis de receptores neuro-hormonais ${ }^{1}$. Pesquisas revelam que diversos sintomas da FM podem ser confundidos com os decorrentes pelas reações hansênicas e que ambas as doenças podem ocorrer concomitantemente ${ }^{5}$. Além disso, pesquisas referem que portadores de FM podem apresentar um nível elevado de hormônio estimulador da tireoide (TSH) indicando associação com hipotireoidismo ${ }^{6,7}$.

Os dados epidemiológicos referentes à prevalência são variáveis, de acordo com diferentes estudos, dependendo da população avaliada e da metodologia aplicada. Com base em pesquisas internacionais, a frequência é de 1 a $5 \%$ na população geral. Nos serviços de clínica médica, essa frequência é em torno de $5 \%$ e nos pacientes hospitalizados de $7,5 \%$. Na clínica reumatológica por sua vez, essa síndrome é detectada em $14 \%$ dos atendimentos. Nos Estados Unidos, acredita-se que 3\% a $6 \%$ da população geral, incluindo a pediátrica, são portadores de FM. No Brasil, alguns trabalhos falam a favor de uma prevalência em torno de $10 \%$ da população geral ${ }^{2,3}$.

A FM é mais frequente no sexo feminino e na faixa etária de 30 a 50 anos com ocorrência em menor grau na população pediátrica ${ }^{3,8}$. Seu diagnóstico é realizado de acordo com critérios estabelecidos pelo Colégio Americano de Reumatologia, em 1990 e que são: ${ }^{1:}$

a) dor difusa com duração no mínimo de três meses nas seguintes regiões: dor nos lados esquerdo e direito do corpo, dor acima e abaixo da linha de cintura, dor no esqueleto axial (coluna cervical ou torácica anterior, ou coluna toráxica, ou coluna lombar). A dor no ombro ou na nádega é considerada como dor para cada lado envolvido.

b) dor em pelo menos 11 dos 18 pontos palpados denominados "tender point" com uma força aproximada de $4 \mathrm{~kg}$. Para que um "tender point' seja considerado positivo, o paciente deve declarar que a palpação foi dolorosa. A presença dos pontos dolorosos é o achado primordial do exame físico.
As opções de tratamento na FM são exercícios de relaxamento, fisioterapia, massagens, irradiação localizada de calor, atividades físicas moderadas em especial exercícios aeróbicos e caminhadas, além da medicação necessária para dor e sintomas associados ${ }^{9}$. A dor é um problema grave nesses pacientes, a qualidade de vida é ruim afetando a capacidade de trabalho ${ }^{9}$.

Em casos mais avançados podem ocorrer ansiedade, angústia, distúrbios do sono ${ }^{10-12}$, de humor, de memória, cefaleia, alucinações (causadas por irritação cerebral e não por desordem mental funcional), e a dificuldade na concentração indica uma redução do fluxo sanguíneo cerebral ${ }^{10,11}$. Esta redução pode indicar disfunção na porção vestibular responsável pelo equilíbrio corporal ${ }^{11}$. Distúrbios da função oculomotora são relatados na FM e podem ocorrer em razão da disfunção nos mecanismos responsáveis pela sua regulação em conseqüência da diminuição do suprimento sanguíneo no labirinto ${ }^{11}$.

Diversas doenças reumatológicas, pelas suas manifestações e áreas de comprometimento, podem gerar alterações vestibulococleares importantes, sendo os testes otoneurológicos ferramentas importantes na confirmação dos distúrbios auditivos e/ou vestibulares e suas relações com o sistema nervoso central ${ }^{13}$.

Diante do exposto, o objetivo do presente estudo é apresentar os achados vestibulococleares em dois casos de FM e ressaltar a importância dos exames nessa doença reumatológica que manifesta diversos sintomas otológicos que podem interferir no convívio social e na capacidade de trabalho prejudicando a qualidade de vida desses pacientes.

\section{APRESENTAÇÃO DOS CASOS}

Avaliaram-se dois pacientes do sexo feminino com diagnóstico de FM, com idades entre 52 e 61 anos, encaminhados ao Setor de Otoneurologia de uma Instituição na cidade de Curitiba/PR. Ambos os pacientes não apresentavam perda auditiva induzida pelo ruído e alterações de orelha média.

Realizaram-se os seguintes procedimentos:

\section{Anamnese}

Aplicou-se um questionário com ênfase aos sinais e sintomas otoneurológicos, antecedentes pessoais e familiares.

\section{Avaliação Otorrinolaringológica}

Realizada pelo médico da clínica de fonoaudiologia com o objetivo de excluir qualquer alteração que pudesse interferir no exame. 


\section{Avaliação Audiológica}

A audiometria tonal limiar convencional foi realizada com um audiômetro de 2 canais, da marca Madsen-GN Otometrics, modelo Itera, com fones TDH-39, com limiares em dB NA. O equipamento encontra-se calibrado de acordo com o padrão ISO 8253. A seguir, pesquisou-se a determinação do limiar de reconhecimento de fala (LRF) e do índice percentual de reconhecimento de fala (IPRF), em cabine acusticamente tratada para impedir a interferência de ruídos estranhos ao teste. Foram aplicados critérios para a caracterização do grau e tipo de perda auditiva ${ }^{14}$.

\section{Avaliação Vestibular}

Os pacientes foram submetidos às seguintes provas que compõem o exame vestibular:

\section{Sem registro}

- Pesquisou-se o nistagmo e a vertigem de posição/posicionamento;

- Pesquisaram-se os nistagmos espontâneo e semi-espontâneo com os olhos abertos, no olhar frontal e a $30^{\circ}$ de desvio do olhar para a direita, esquerda, para cima e para baixo.

\section{Com registro}

Para a realização da vectoeletronistagmografia (VENG) utilizou-se um aparelho termossensível, com três canais de registro, da marca Berger, modelo VN316. Colocaram-se, fixados com pasta eletrolítica, um eletródio ativo no ângulo lateral de cada olho e na linha média frontal, formando um triângulo isósceles, que permitiu a identificação dos movimentos oculares horizontais, verticais e oblíquos. Este tipo de VENG possibilitou obter medidas mais precisas da velocidade angular da componente lenta (VACL) do nistagmo.

Utilizou-se uma cadeira rotatória pendular decrescente da marca Ferrante, um estimulador visual modelo EV VEC e um otocalorímetro a ar modelo NGR 05 ambos da marca Neurograff.

Realizaram-se as seguintes provas oculares e labirínticas à VENG, de acordo com critérios anteriormente propostos ${ }^{15}$.

- Calibração dos movimentos oculares: nesta etapa do exame, o aspecto clínico avaliado foi a regularidade do traçado, tornando as pesquisas comparáveis entre si.

- Pesquisa dos nistagmos espontâneo (olhos abertos e fechados) e semi-espontâneo (olhos abertos): neste registro avaliaram-se a ocorrência, direção, efeito inibidor da fixação ocular (EIFO) e o valor da VACL máxima do nistagmo.

- Pesquisa do rastreio pendular para a avaliação da ocorrência e do tipo de curva.
- Pesquisa do nistagmo optocinético à velocidade de $60^{\circ}$ por segundo, nos sentidos anti-horário $(\mathrm{AH})$ e horário $(\mathrm{H})$, na direção horizontal. Avaliaram-se a ocorrência, direção, VACL máxima às movimentações anti-horária e horária do nistagmo.

- Pesquisa dos nistagmos pré e pós-rotatórios à prova rotatória pendular decrescente, com estimulação dos ductos semicirculares laterais, anteriores e posteriores. Observaram-se a ocorrência, direção, frequência às rotações antihorária e horária do nistagmo.

- Pesquisa dos nistagmos pré e pós-calóricos realizada com o paciente posicionado de forma que a cabeça e o tronco estivessem inclinados $60^{\circ}$ para trás, para estimulação adequada dos ductos semicirculares laterais. O tempo de irrigação de cada orelha com ar a $42^{\circ} \mathrm{C}$ e $18^{\circ} \mathrm{C}$ durou 80 s para cada temperatura e as respostas foram registradas com os olhos fechados e, a seguir, com os olhos abertos para a observação do EIFO. Nesta avaliação verificaram-se a direção, os valores absolutos da VACL e o cálculo das relações da preponderância direcional e predomínio labiríntico do nistagmo pós-calórico.

A pesquisa foi realizada após autorização dos pacientes por meio de assinatura do Termo de Consentimento Livre e Esclarecido e foi aprovada pelo Comitê de Ética em Pesquisa em Humanos e Animais da Universidade Tuiuti do Paraná, protocolo número 000187/2009.

\section{RESULTADOS}

Paciente 1 - sexo feminino, 52 anos, refere tontura constante, em crises que duram dias, acompanhada de sensação de que os objetos giram ao seu redor, com piora ao movimento da cabeça e em determinadas posições do corpo, principalmente quando gira em ambos os lados. Relata pressão na cabeça, desequilíbrio à marcha para direita, zumbido contínuo à direita e de intensidade variável, fadiga, depressão, cefaleia, dificuldade em escutar, dificuldade nos movimentos do pescoço entre outros (sic).

O diagnóstico da FM foi realizado no início do ano 2000 , sendo medicada desde então.

Avaliação Audiológica: Perda auditiva do tipo neurossensorial a partir de $2 \mathrm{KHz}$ na orelha esquerda (OE) e limiares auditivos dentro dos padrões de normalidade na orelha direita (OD).

Avaliação vestibular:

- Nistagmo de posição e/ou posicionamento: ausente; 
- Calibração dos movimentos oculares: regular;

- Nistagmo espontâneo: olhos abertos: ausente; olhos fechados: ausente;

- Nistagmo semi-espontâneo: ausente;

- Rastreio pendular: Tipo II;

- Nistagmo optocinético: simétrico com VACL $\mathrm{AH}=6 \%$ s; VACL H $=6 \%$ s;

- Nistagmo per-rotatório: estimulação dos ductos semicirculares laterais: simétricos com frequência nistágmica: $\mathrm{AH}=9 ; \mathrm{H}=9$; $\mathrm{PDN}=0 \%$. Estimulação dos ductos semicirculares posteriores: simétricos com frequência nistágmica: $\mathrm{AH}=7$; $\mathrm{H}=8$; $\mathrm{PDN}=7 \%$ à direita. Estimulação dos ductos semicirculares anteriores: simétricos com frequência nistágmica: $\mathrm{AH}=8 ; \mathrm{H}=7 ; \mathrm{PDN}=7 \%$ à esquerda;

- Nistagmo pós-calórico: prova calórica realizada com ar; $42^{\circ} \mathrm{C}$ OD: $\mathrm{VACL}=3 \% \mathrm{~s} ; 42^{\circ} \mathrm{C}$ OE: $\mathrm{VACL}=14 \%$ s; $18^{\circ} \mathrm{C}$ OD: $\mathrm{VACL}=10^{\circ} / \mathrm{s} ; 18^{\circ} \mathrm{C}$ $\mathrm{OE}: \mathrm{VACL}=17 \%$ s. Presença de EIFO nas quatro estimulações;

Achados no exame: predomínio labiríntico de $41 \%$ à esquerda.

Conclusão do exame: sugestivo de síndrome vestibular periférica deficitária à direita.

Paciente 2 - sexo feminino, 61 anos, refere tontura intensa, constante, piora ao movimentar a cabeça e em veículos em movimento, com sensação de oscilação, cabeça oca, escurecimento de visão, pressão na cabeça, náuseas, sudorese, palidez, palpitação, desequilíbrio à marcha para frente com desvio para direita e quedas. Refere zumbido na OE tipo contínuo e frequente, com piora nas crises vertiginosas. Possui dificuldade para dormir devido ao zumbido, relata fadiga, depressão e cefaleia (sic).

Avaliação Audiológica: Limiares auditivos dentro dos padrões de normalidade bilateralmente.

\section{Avaliação vestibular:}

- Nistagmo de posição e/ou posicionamento: não foi possível realizar pela dificuldade da paciente;

- Calibração dos movimentos oculares: regular;

- Nistagmo espontâneo: olhos abertos: ausente; olhos fechados: ausente;

- Nistagmo semi-espontâneo: ausente;

- Rastreio pendular: Tipo I;

- Nistagmo optocinético: simétrico com VACL AH $=10 \% \mathrm{~s} ; \mathrm{VACL} \mathrm{H}=10 \% \mathrm{~s}$;

- Nistagmo per-rotatório: A paciente não se sentiu confortável, referiu muito medo não permitindo a realização desta prova;
- Nistagmo pós-calórico: prova calórica realizada com ar; $42^{\circ} \mathrm{C}$ OD: $\mathrm{VACL}=40^{\circ} / \mathrm{s} ; 42^{\circ} \mathrm{C}$ OE: $\mathrm{VACL}=18 \%$ s. Não foi possível realizar a estimulação à $18^{\circ} \mathrm{C}$ em ambas orelhas, a paciente apresentou intensa manifestação neurovegetativa.

Achados no exame: hiperreflexia em valor absoluto à prova calórica $42^{\circ} \mathrm{C} \mathrm{OD}$. Conclusão do exame: sugestivo de síndrome vestibular periférica irritativa à direita.

\section{DISCUSSÃO}

De acordo com a literatura compulsada sintomas de tontura e zumbido são comumente referidos na FM 1,11,16,17. Segundo os autores ${ }^{17}$ em seus estudos referiram que $72 \%$ dos pacientes apresentaram vertigem e tontura enquanto que 30\% apresentaram perda auditiva. Para os autores ${ }^{16}$ os sintomas vestibulares podem decorrer de anormalidades musculoesqueléticas comuns na FM e estas podem afetar a propriocepção provocando uma sensação de instabilidade.

Com relação aos achados audiológicos, observou-se perda auditiva do tipo neurossensorial (PANS) na OE em apenas um caso. Os autores ${ }^{16}$ relatam que pacientes com FM podem apresentar diminuição da audição e intolerância a sons intensos. Estudos desenvolvidos pelos autores ${ }^{17}$ referem PANS não referindo seu grau e resultados anormais na pesquisa do potencial evocado auditivo de tronco encefálico em $30 \%$ dos pacientes avaliados. Outro estudo ${ }^{11}$ observou também PANS em $15 \%$ de seus pacientes, sendo, $10 \%$ de grau leve, $4 \%$ de grau moderado e $1 \%$ de grau severo.

O equilíbrio corporal depende da integridade do sistema vestibular, labirinto, nervo vestibulococlear, núcleos, vias e interrelações do SNC, do sistema somatossensorial e da visão. Tonturas e/ou desequilíbrio surgem quando algo interfere no funcionamento normal do sistema de equilíbrio corporal ${ }^{18}$.

$O$ estudo do nistagmo realizado por meio da VENG tem-se constituído como um recurso preciso no diagnóstico topográfico de várias doenças. Nas síndromes otoneurológicas centrais observa-se que os sinais de afecção do sistema vestibular central são predominantes em diversas provas labirínticas, fato que não ocorre nas síndromes periféricas ${ }^{15}$.

Nos casos relatados, ao exame vestibular, observou-se alteração apenas na prova calórica, ocorrendo uma hiper-reflexia labiríntica em valor absoluto na prova calórica $42^{\circ} \mathrm{C}$ OD e em outro caso, um predomínio labiríntico à esquerda demonstrando uma hipo-reflexia no labirinto oposto. Em todas as estimulações, em ambos os casos, houve a presença do EIFO. 
$\mathrm{Na}$ literatura compulsada com relação à avaliação vestibular, os autores ${ }^{11}$ referiram presença dos nistagmos posicional e espontâneo de olhos abertos com e sem fixação ocular, alterações nos movimentos sacádicos, na velocidade do rastreio pendular e presença de hipo e hiperreflexias à estimulação calórica. Os autores ${ }^{11}$ encontraram 35\% de disfunção do sistema vestibular com envolvimento do SNC e os autores ${ }^{16}$ observaram disfunção periférica com alteração somente na prova calórica com presença de hipo e hiperreflexias.

$\mathrm{Na}$ literatura compulsada com relação à parte otoneurológica, encontraram-se poucos estudos atuais, mas, os utilizados na presente pesquisa, referiram alterações importantes em provas que compõem o exame labiríntico, o que ressalta que esse tipo de população deveria ser melhor investigada, uma vez que, diversas doenças reumatológicas pelas suas manifestações e áreas de comprometimento podem gerar alterações vestibulococleares importantes que muitas vezes passam despercebidas e podem interferir no convívio social e na capacidade de trabalho com prejuízo da qualidade de vida desses pacientes.

\section{CONCLUSÃO}

Os casos apresentados demonstraram a importância das avaliações audiológica e vestibular na contribuição da elaboração de estratégias utilizadas no acompanhamento terapêutico da FM sugerindo a realização desses exames como rotina clínica.

\begin{abstract}
Background: fibromyalgia is a non-inflammatory musculoskeletal syndrome, with a chronic nature and unknown aetiology, characterized by widespread pain, increase in sensibility to palpation and by symptoms such as insomnia, stiffness, fatigue, psychological sickness, intolerance to cold and otologic complaints. Procedures: two female patients diagnosed with fibromyalgia, aged 52 to 61 years, were evaluated in the Otoneurology sector of a institution, in September 2008, and consulted for: dizziness, paraesthesia, perception of movement of objects, imbalance on walking, falls, fatigue, depression, headaches, and difficulty in listening and moving the neck. They were submitted to the following procedures: anamnesis, otological inspection, audiologic evaluation and vestibular exam through vectoelectronystagmography. Results: the following discoveries were noted: Patient 1 hearing loss of the sensorineural type from $2 \mathrm{KHz}$ in the left ear, normal hearing thresholds in the right ear and hypo-reflexia with an absolute value of $42^{\circ} \mathrm{C}$ in the caloric test in the right ear. Patient 2 - normal hearing thresholds, bilaterally, and hyper-reflexia with an absolute value of $42^{\circ} \mathrm{C}$ in the caloric test in the right ear with an intense neurovegetative manifestation. Conclusion: the submitted cases demonstrated the importance of audiologic evaluations and vestibular exams in the contribution to elaboration of strategies used in the therapeutic consolidation of fibromyalgia suggesting the performance of those exams as a clinical routine.
\end{abstract}

KEYWORDS: Fibromyalgia; Vertigo; Vestibular Function Tests; Hearing

\section{REFERÊNCIAS}

1. Helfenstein M, Feldman D. Síndrome da fibromialgia: características clínicas e associações com outras síndromes disfuncionais. Rev Bras Reumatol. 2002; 42(1):8-14.

2. Fibromialgia.com.br. [homepage da internet]. São Paulo: Aspen [acesso em 2009 fev 28]. Disponível em: URL: http://www.fibromialgia.com.br

3. Sánchez MAT. Fibromialgia. Colomb Med. 2005; 36(4):287-91.

4. Riberto M, Pato TR. Fisiopatologia da fibromialgia. Acta Fisiátrica. 2004; 11(2):78-81.
5. Carneiro SCS. Fibromialgia e reação hansênica. Rev Bras Reumatol. 2006; 46(1):77-9.

6. Rezende LS, Rezende LS, Radominski SC, Paiva ES. A relevância da dosagem do hormônio estimulante da tireóide em pacientes com fibromialgia. Rev Bras Reumatol. 2006; 46(1):73-4.

7. Freire M, Teodoro RB, Oliveira LB, Cunha SFC, Ferreira BP, Borges MF. Concomitância de fibromialgia em pacientes portadores de hipotireoidismo e de alterações tireoideanas em pacientes com fibromialgia. Rev Bras Reumatol. 2006; 46(1):11-5. 
8. Shaver JL. Fibromyalgia syndrome in women. Nurs Clin North Am. 2004; 39(1):195-204.

9. Feldman D. Fibromialgia e síndrome miofascial: vai ou não vai? [editorial] Rev Bras Reumatol. 2008; 48(6):318.

10. Mease P. Fibromyalgia syndrome: review of clinical presentation, pathogenesis, outcome measures, and treatment. J Rheumatol Suppl. 2005; 32(75):6-21.

11. Rosenhall $U$, Johansson G, Orndahl G. Otoneurologicandaudiologic findings infibromyalgia. Scand J Rehabil Med. 1996; 28(4):225-32.

12. Araújo RL. Fibromialgia: construção e realidade na formação dos médicos. Rev Bras Reumatol. 2006; 46(1):56-60.

13. Ganança MM, Munhoz MSL, Caovilla HH, Silva MLG. Introdução: conceitos em otoneurologia. In: Ganança MM, Munhoz MSL, Caovilla HH, Silva MLG. Otoneurologia ilustrada. São Paulo: Atheneu; 2005. p.1-5.
14. Davis $H$, Silverman RS. Hearing and deafness. 3. ed. New York: Holt, Rinehart \& Wilson; 1970. p.253-79.

15. Mangabeira-Albernaz PL, Ganança MM, Pontes PAL. Modelo operacional do aparelho vestibular. In: Mangabeira-Albernaz PL, Ganança MM. Vertigem. 2.ed. São Paulo: Moderna; 1976. p.29-36.

16. Hadj-djilani A, Gerster JC. Hearing and vestibular abnormalities in primary fibrositis syndrome. J Rheumatol. 1984; 11(5):678-80.

17. Bayazit YA, Gürsoy $S$, Özer E, Karakurum G, Madenci E. Neurotologic manifestations of the fibromyalgia syndrome. J Neurol Sci. 2002; 196(1-2):77-80.

18. Munhoz MSL, Silva MLG, Ganança MM, Caovilla $\mathrm{HH}$. O diagnóstico otoneurológico integrado. In: Ganança MM, Munhoz MSL, Caovilla HH, Silva MLG. Otoneurologia ilustrada. São Paulo: Atheneu; 2005. p.5-11.

DOI: 10.1590/S1516-18462010005000065

RECEBIDO EM: 22/04/2009

ACEITO EM: 03/11/2009

Endereço para correspondência:

Bianca Simone Zeigelboim

Rua Gutemberg, 99 9 andar

Curitiba - PR

CEP: 80420-030

E-mail: bianca.zeigelboim@utp.br 